\title{
Study of Scale and Corrosion Inhibition Performances of Polyaspartic Acid
}

\author{
Yushan Cheng ${ }^{1, a}$, Yanmin Chen ${ }^{2, b}$, Yincong Sun ${ }^{3, c}$, \\ Caixia Sun ${ }^{4, d}$ and Changshan Huang ${ }^{5, e}$ \\ 1,2,3,4,5 Institute of Energy Research, Henan Academy of Sciences, China \\ a,b,c,d,e chengyushan09@163.com
}

Keywords: Polyaspartic acid. Scale inhibition. Corrosion inhibition. Circulating cooling water

Abstract. In this article, the scale and corrosion inhibition performances of Polyaspartic acid (PASP) and PASP-based composite were studied. The results showed the single PASP has good scale and corrosion inhibition performances, but the quantity of PASP used for corrosion inhibition is large $(100 \mathrm{mg} / \mathrm{L})$. To reduce cost, PASP-based composite was prepared from PASP, BTA, sodium tungstate and sodium gluconate with different scales. The optimal proportioning mass ratio is as follows: PASP : BTA : sodium tungstate : sodium gluconate is $10: 0.5: 20: 10$ (total concentration: $40.5 \mathrm{mg} / \mathrm{L}$ ). Experimental results showed the corrosion rate of HSn-70A copper is only 0.0006 $\mathrm{mm} / \mathrm{a}$ and corresponding corrosion inhibiting rate reaches $99.22 \%$. The small dynamic simulation showed that inhibition rate of this PASP-based composite can reach more than $90 \%$ even in high hardness and concentration.

\section{Introduction}

With the enhancement of people's consciousness in environmental protection, it becomes more and more important to study the environment-friendly corrosion inhibitors ${ }^{[1-3]}$. Polyaspartic acid has been widely used in water treatment and other fields for many advantages, such as no phosphorus, non-toxic, no pollution, easy biodegradation, especially the double functions with both corrosion and scale inhibition properties ${ }^{[4-5]}$. PASP has a linear polyamide structure, similar to the amide bond structure of protein, and has good biocompatibility. It can be degraded completely and has no effect on the environment ${ }^{[6]}$. In the current study, more and more people began to consider PASP as a substitute for green water treatment agent. The main purpose of this paper is to test the polyaspartic acid and its composite performances of scale and corrosion inhibition in different conditions.

\section{Experimental Part}

\section{Static scale inhibition test ${ }^{[7]}$}

Reagents Calcium chloride anhydrous, seven water magnesium sulfate, Sodium bicarbonate, Sodium hydroxide, Borax, Calcium carboxylic acid, Methyl red, Bromine cresol green, 95\% ethanol, these reagents are all analytically pure. Hydrochloric acid is the standard titration solution, EDTA is a guaranteed reagent, PASP using commercially available industrial products.

Test method (1) According to the GB/T16632-1996 "scale inhibition performance of water treatment agents Determination of calcium carbonate deposition method". In the water solution, the concentration of $\mathrm{Ca}^{2+}$ is $6 \mathrm{mmol} / \mathrm{L}$, the concentration of $\mathrm{HCO}_{3}{ }^{-}$is $12 \mathrm{mmol} / \mathrm{L}$. The test temperature of $80 \pm 1{ }^{\circ} \mathrm{C}$ (constant temperature water bath heat preservation, similarly hereinafter), test time 10 h. (2) The water hardness is greater than the alkalinity. The concentration of $\mathrm{Ca}^{2+}$ is $12 \mathrm{mmol} / \mathrm{L}$, $\mathrm{HCO}_{3}{ }^{-}$concentration $12 \mathrm{mmol} / \mathrm{L}, \mathrm{Mg}^{2+}$ concentration $4 \mathrm{mmol} / \mathrm{L}, \mathrm{SO}_{4}{ }^{2-}$ concentration $4 \mathrm{mmol} / \mathrm{L}$, 
temperature $55 \pm 1{ }^{\circ} \mathrm{C}$; test time $10 \mathrm{~h}$. (3) The water hardness is less than the alkalinity. The concentration of $\mathrm{Ca}^{2+}$ is $5.5 \mathrm{mmol} / \mathrm{L}, \mathrm{HCO}_{3}{ }^{-}$concentration $20 \mathrm{mmol} / \mathrm{L}, \mathrm{Mg}^{2+}$ concentration 2 $\mathrm{mmol} / \mathrm{L}, \mathrm{SO}_{4}{ }^{2-}$ concentration $2 \mathrm{mmol} / \mathrm{L}$, temperature $55 \pm 1^{\circ} \mathrm{C}$; test time $10 \mathrm{~h}$.

The scale inhibition performance of water treatment agents were expressed as a percentage calculated according to the formula (1):

$$
\eta=\frac{X-X_{0}}{A-X_{0}} \times 100 \%
$$

In the formula (1), $\mathrm{X}$ representative join the test of water treatment agent, the concentration of $\mathrm{Ca}^{2+}$ after the test, the unit is $\mathrm{mg} / \mathrm{mL} ; \mathrm{X}_{0}$ representative the blank solution without adding water treatment agent, the concentration of $\mathrm{Ca}^{2+}$ after the test, the unit is $\mathrm{mg} / \mathrm{ml}$; A representative the concentration of $\mathrm{Ca}^{2+}$ before the test configuration good solution, the unit is $\mathrm{mg} / \mathrm{ml}$. ( Remarks : in the national standard method, $A=0.240 \mathrm{mg} / \mathrm{ml}$; the test solution hardness is greater than the alkalinity, $A=0.401 \mathrm{mg} / \mathrm{ml}$; the test solution hardness is less than the alkalinity, $A=0.216 \mathrm{mg} / \mathrm{ml}$.)

\section{Rotary coupon test $[8]$}

Reagents, test piece and instrument Calcium chloride anhydrous, Seven water magnesium sulfate, Sodium bicarbonate, Sodium hydroxide, Acetone, Anhydrous ethanol, D- sodium gluconate, BTA, Sodium tungstate, these reagents are analytically pure. PASP used commercially available industrial products. The specimen is HSn-70A type copper. Test instrument used RCC-1 type rotary coupon corrosion test instrument.

Test method Experiments using GB/T18175-2000 "corrosion inhibition performance of water treatment agents Determination of rotating hanging plate". Preparation method of the test solution by national standard recommended (Table 1); test temperature of $45 \pm 1^{\circ} \mathrm{C}$; test time $72 \mathrm{~h}$.

Table 1. Preparation of standard solution

\begin{tabular}{llllll}
\hline Ion species & $\mathrm{Ca}^{2+}$ & $\mathrm{Mg}^{2+}$ & $\mathrm{SO}_{4}{ }^{2-}$ & $\mathrm{Cl}^{-}$ & $\mathrm{HCO}_{3}^{-}$ \\
\hline concentration / mg/L & 200 & 48 & 192 & 754 & 122 \\
\hline
\end{tabular}

The corrosion rate calculation formula (2):

$$
X=\frac{87600 \times\left(m-m_{0}\right)}{s \cdot \rho \cdot t}
$$

In the formula (2), $\mathrm{X}$ representative corrosion rate; $\mathrm{m}$ representative the test piece quality loss, the unit is $\mathrm{g} ; \mathrm{m}_{0}$ representative the pickling blank specimen quality loss, the unit is $\mathrm{g}$; $\mathrm{s}$ representative the specimen surface area, the unit is $\mathrm{cm}^{2} ; \rho$ representative the specimen density, the unit is $\mathrm{g} / \mathrm{cm}^{3}$; $t$ representative test time, the unit is $\mathrm{h}$.

The inhibition rate calculation formula (3):

$$
X_{2}=\frac{X_{0}-X_{1}}{X_{0}} \times 100 \%
$$

In the formula (3), $X_{2}$ representative inhibition rate; $X_{0}$ representative the corrosion rate of the 
blank test, the unit is $\mathrm{mm} / \mathrm{a} ; \mathrm{X}_{1}$ representative the inhibition rate of the test piece, the unit is $\mathrm{mm} / \mathrm{a}$. Small dynamic simulation test ${ }^{[9]}$

The DRDT type scale inhibition testing instrument made in Dalian. Experimental water by adding calcium chloride solution was the tap water in Zhengzhou City, total hardness is $658 \mathrm{mg} / \mathrm{L}$, the content of $\mathrm{Ca}^{2+}$ (in terms of calcium carbonate) is $482 \mathrm{mg} / \mathrm{L}$, total alkalinity (in terms of calcium carbonate) is $343 \mathrm{mg} / \mathrm{L}$. The test solution volume is $65 \mathrm{~L}$; the circulating liquid temperature $40{ }^{\circ} \mathrm{C}$; the circulating liquid temperature between the inlet and outlet of the difference of $5^{\circ} \mathrm{C}$, the circulating water $200 \mathrm{~L} / \mathrm{h}$. Periodic sampling, detection of concentration of $\mathrm{Ca}^{2+}$ and $\mathrm{Cl}^{-}$. Then, according to the concentration ratio of $\mathrm{Ca}^{2+}$ and $\mathrm{Cl}^{-}$ratio, calculate the scale inhibition rate.

\section{Results and discussion}

\section{Determination of scale inhibition performance of PASP}

Experiment 1 In accordance with the GB/T16632-1996 "Scale inhibition performance of water treatment agents determination of calcium carbonate deposition method". The scale inhibition rates of PASP under different dosage were determined, the test result shows in figure 1.

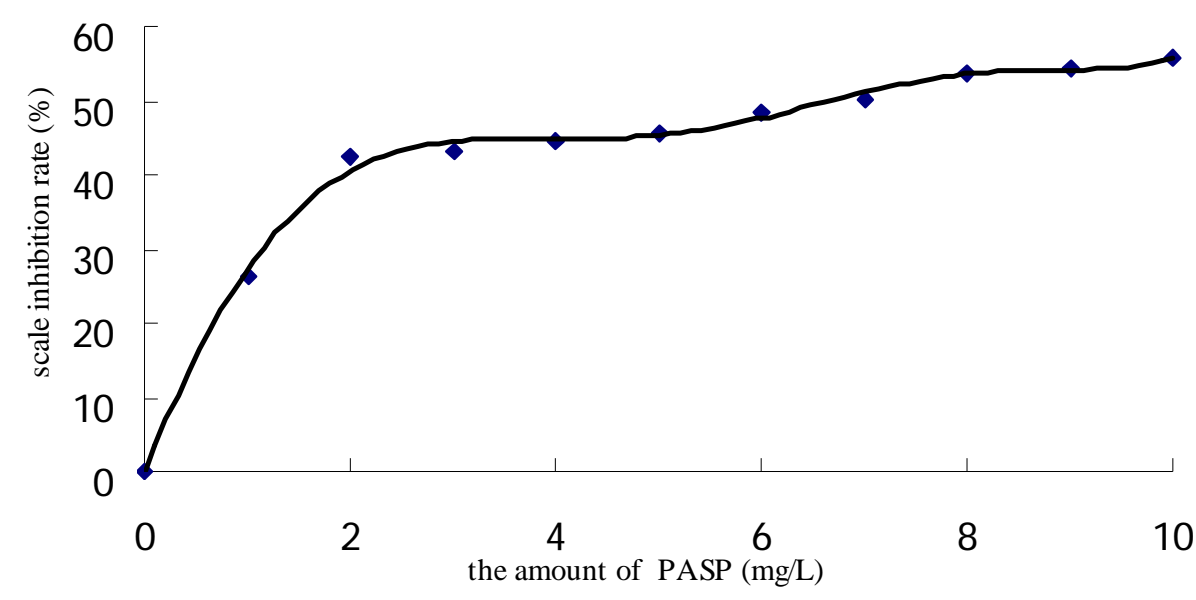

Fig.1. The amount of PSAP and the scale inhibition rate curve at $80^{\circ} \mathrm{C}$

As shown in Figure 1, the PASP scale inhibition rate increased along with the concentration increase. In the low concentration of PASP $(\leq 2 \mathrm{mg} / \mathrm{L})$, rate of scale inhibition curve slope is larger, the scale inhibition rate increased rapidly with the PASP content increase; When the concentration of PASP is higher than $2 \mathrm{mg} / \mathrm{L}$, the scale inhibition rate slowly growth with the PASP content increase until the concentration of PASP reached $10 \mathrm{mg} / \mathrm{L}$, then the scale inhibition rate to reach $55.8 \%$. Obviously, at $80^{\circ} \mathrm{C}$, PASP scale inhibition rate is not high and the scale effect is not ideal. Considering the actual circulating water temperature often below $45^{\circ} \mathrm{C}$, reduce the test temperature appropriate. So PASP scale inhibition test is carried out at $55^{\circ} \mathrm{C}$ (see Experiment 2 and Experiment 3).

Experiment 2 Experimental water hardness is greater than the alkalinity. The scale inhibition rate of PASP was determined under different dosage, the results shown in figure 2. 


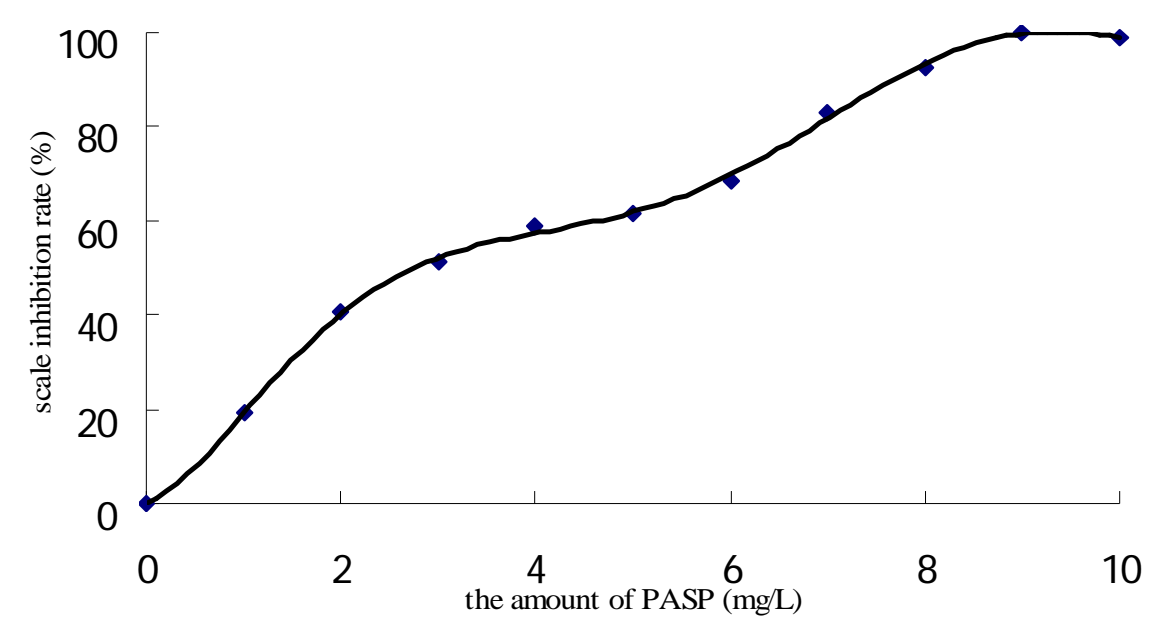

Fig.2. The amount of PSAP and the scale inhibition rate curve at 55C

Experiment 3 Experimental water hardness is less than the alkalinity. The scale inhibition rates of PASP under different dosage were determined, the results shown in figure 3.

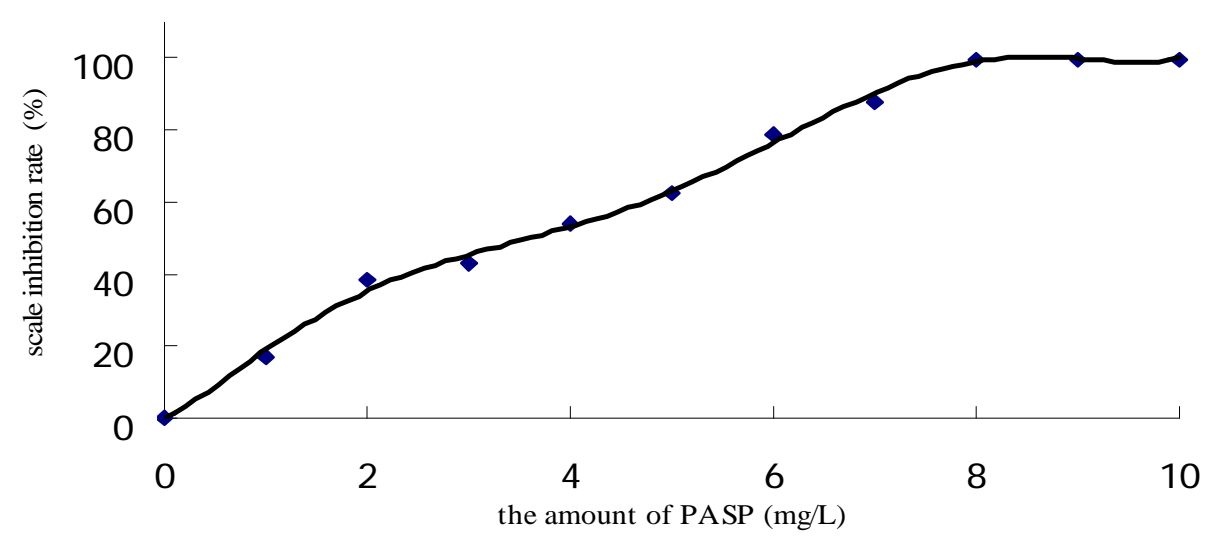

Fig.3. At $55^{\circ} \mathrm{C}$, the amount of PSAP and the scale inhibition rate curve

As shown in Figure 2 and figure 3: Compared with the PASP scale inhibition effect at $80{ }^{\circ} \mathrm{C}$, the result is better at $55^{\circ} \mathrm{C}$. When water hardness is greater than the alkalinity and dosage of PASP was $9 \mathrm{mg} / \mathrm{L}$, the scale inhibition rate reached $100 \%$. When water hardness is less than the alkalinity and the dosage of PASP was $8 \mathrm{mg} / \mathrm{L}$, the scale inhibition rate reached $100 \%$. The results of Experiment 2 and Experiment 3 indicate that PASP showed good scale inhibition performance at relatively low temperature $\left(55^{\circ} \mathrm{C}\right)$.

\section{Determination of corrosion inhibition performance of PASP}

The different concentrations of PASP were added to the test solution (the test solution as shown in Table 1). Test method is same as 2.2.2. Determination of corrosion inhibition rate using copper specimen (hsn-70a), the results as shown in figure 4. 


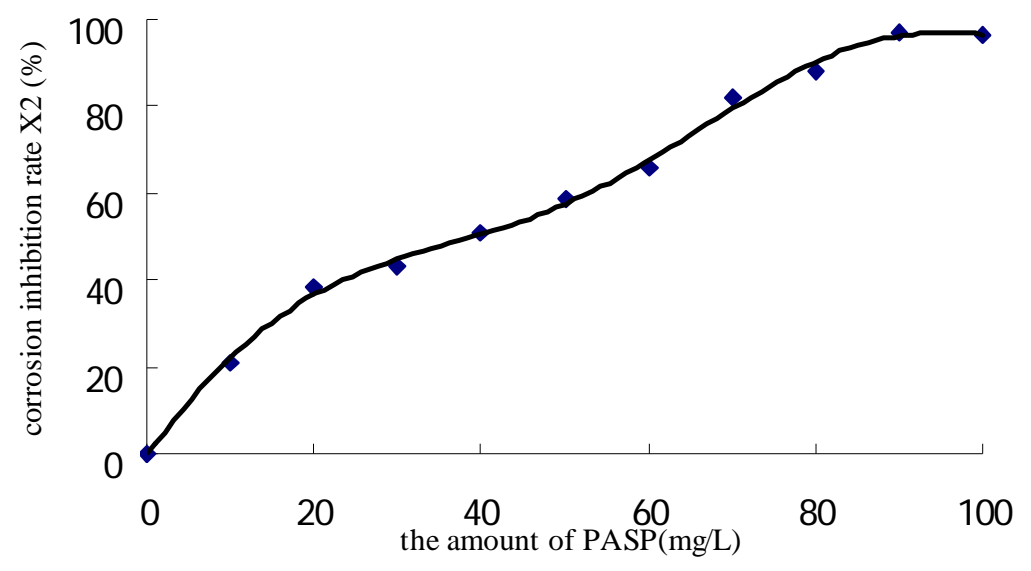

Fig.4. The amount of PSAP and the corrosion inhibition rate curve

As shown in Figure 4, the HSn-70A copper specimen corrosion inhibition rate was gradually increased with the increase of the concentration of PASP. Although having a good corrosion inhibition effect, but the concentration of PASP is high. So, the use of PASP alone as a corrosion inhibitor is not economical way. Therefore, in order to reduce the amount of PASP and enhance the corrosion inhibition rate, it is necessary to develop PASP-based composite formula.

\section{Study on synergistic effect of compound formula}

PASP is a new biodegradable water treatment agent. BTA is a kind of high efficient copper inhibitor, form protective membrane by chemical adsorption, less dosage, good corrosion inhibition effect. Inhibition effect of sodium tungstate on copper is mainly due to weak oxidizing action between sodium tungstate and copper and then forming a cuprous oxide or copper oxide film on the copper surface. Sodium gluconate has the advantages of low cost and has good synergistic effect on chemical compound corrosion inhibitor.

Using the orthogonal test method (four factors and two levels) with PASP, BTA, sodium tungstate and sodium gluconate as the object study, the synergistic effects between the four element compound formula was studied. 
Table 2. The results of orthogonal test

\begin{tabular}{|c|c|c|c|c|c|c|}
\hline $\begin{array}{c}\text { Test } \\
\text { scheme }\end{array}$ & $\begin{array}{c}\text { PASP } \\
(\mathrm{mg} / \mathrm{L})\end{array}$ & $\begin{array}{c}\text { BTA } \\
(\mathrm{mg} / \mathrm{L})\end{array}$ & $\begin{array}{l}\text { Sodium } \\
\text { tungstat } \\
\mathrm{e} \\
(\mathrm{mg} / \mathrm{L})\end{array}$ & $\begin{array}{l}\text { Sodium } \\
\text { glucona } \\
\text { te } \\
(\mathrm{mg} / \mathrm{L})\end{array}$ & $\begin{array}{l}\text { Corrosion } \\
\text { rate } \\
(\mathrm{mm} / \mathrm{a})\end{array}$ & $\begin{array}{c}\text { Inhibition } \\
\text { rate } \\
(\%)\end{array}$ \\
\hline 1 & 10 & 0.5 & 10 & 10 & 0.0023 & 94.56 \\
\hline 2 & 10 & 0.5 & 10 & 20 & 0.0031 & 91.87 \\
\hline 3 & 10 & 1 & 20 & 10 & 0.0015 & 98.02 \\
\hline 4 & 10 & 1 & 20 & 20 & 0.0019 & 96.13 \\
\hline 5 & 20 & 0.5 & 20 & 10 & 0.0024 & 94.47 \\
\hline 6 & 20 & 0.5 & 20 & 20 & 0.0016 & 97.14 \\
\hline 7 & 20 & 1 & 10 & 10 & 0.0035 & 91.98 \\
\hline 8 & 20 & 1 & 10 & 20 & 0.0039 & 91.25 \\
\hline 9 & - & - & - & - & 0.0523 & \\
\hline $\begin{array}{c}\text { Average } \\
1\end{array}$ & 95.145 & 94.510 & 92.415 & 94.757 & & \\
\hline $\begin{array}{c}\text { Average } \\
2\end{array}$ & 93.710 & 94.345 & 96.440 & 94.097 & & \\
\hline Range & 1.435 & 0.165 & 4.025 & 0.660 & & \\
\hline
\end{tabular}

As shown Table 2, in the eight test schemes, the copper corrosion rate are all less than $0.005 \mathrm{~mm} / \mathrm{a}$, which meet the GB/50050 - 2007 "industrial circulating cooling water treatment design specification" requirement. Because the fully synergistic effect between the four kinds of compounds, even at low concentration levels, corrosion inhibition can achieve good effect.

Formula 3 is the best combination scheme in Table 2: 10mg/L PASP+1mg/L BTA+ $20 \mathrm{mg} / \mathrm{L}$ sodium tungstate $+10 \mathrm{mg} / \mathrm{L}$ sodium gluconate. The corrosion rate was only $0.0015 \mathrm{~mm} / \mathrm{a}$ and the inhibition rate reached $98.02 \%$. Through the analysis of the average and range of each factor, we can get the formula which has best inhibition effect should be $10 \mathrm{mg} / \mathrm{L}$ PASP+0.5 mg/L BTA+ 20 $\mathrm{mg} / \mathrm{L}$ sodium tungstate $+10 \mathrm{mg} / \mathrm{Lsodium}$ gluconate. We also carried out supplemented experiments to verify this formula, the results indicated that the copper corrosion rate was $0.0006 \mathrm{~mm} / \mathrm{a}$ and inhibition rate reached $99.22 \%$, consistent with the results of orthogonal test. Therefore, we recognized complement the experimental formula as the optimal compound formula.

\section{Small dynamic simulation test}

The water treatment agent in the circulating cooling water is existed in the form of flow, according to the experimental method2.3, we carried out small dynamic simulation test to study on the four element composite formula. The results as shown in table 3.

Table 3. The results of small dynamic simulation test

\begin{tabular}{ccc}
\hline $\mathrm{Ca}^{2+}$ Concentration ratio & 'TConcentration ratio & $\begin{array}{c}\text { Scale inhibition rate } \\
(\%)\end{array}$ \\
\hline 1.0 & 1.0 & 100 \\
1.5 & 1.5 & 100 \\
2.0 & 2.09 & 95.7 \\
2.5 & 2.71 & 92.3 \\
3.0 & 3.32 & 90.4 \\
\hline
\end{tabular}

Table 3 shows that circulating water hardness is $658 \mathrm{mg} / \mathrm{L}$, temperature is $40{ }^{\circ} \mathrm{C}$, four element 
compound formula scale inhibition effect is very excellent. The scale inhibition rate reached $90 \%$ even under the high concentration ratio conditions. Therefore, the four element compound formula can be used in the circulating water even in high hardness and high concentration ratio.

\section{Conclusions}

PASP has very good scale inhibition effect. Whether in high alkalinity and high hardness conditions, constant temperature of $55^{\circ} \mathrm{C}$, test time $10 \mathrm{~h}$, adding $8-9 \mathrm{mg} / \mathrm{L}$ PASP can completely block the calcium carbonate scale, the scale inhibition rate reaches $100 \%$. The HSn-70A copper corrosion inhibition rate with the increase of the concentration of PASP was gradually increasing trend, in order to achieve good corrosion inhibition effect, requires a higher concentration of PASP, therefore, PASP compound formula is very necessary. The optimal compound formula is $10 \mathrm{mg} / \mathrm{LPASP}+0.5 \mathrm{mg} / \mathrm{LBTA}+20 \mathrm{mg} / \mathrm{L}$ sodium tungstate $+10 \mathrm{mg} / \mathrm{L}$ sodium gluconate, through the experiments of the formula, the copper corrosion rate was $0.0006 \mathrm{~mm} / \mathrm{a}$ and inhibition rate reached 99.22\%.The of small dynamic simulation test shows very excellent results, the results demonstrated that the four element compound formula can be used in the circulating water even in high hardness and high concentration ratio.

\section{References}

[1]Qunjie Xu, Kongxiang Dong: Corrosion and protection, Vol.26(10)(2005), p.415(in Chinese)

[2]Yan Li,Zhu Lu: Materials Protection, 2003(9), p.46(in Chinese)

[3] Wei Wang; Guoding Zhou: Materials Protection, 2006(7), p.46(in Chinese)

[4]Guolin Jing,Shuzhi Liu: Industrial water treatment, 2003(11), p.67(in Chinese)

[5]Kecheng Wang, Xin Liu, Lihong Wang: Materials Protection, 2007(6), p.57(in Chinese)

[6]Ke Cui, Ke Zhang: Applied chemical industry, Vol.28(4)(2009), p.42(in Chinese)

[7]Yingmin Chen,Li Cui: Thermal power generation, Vol.38(7)(2009), p.40-43(in Chinese)

[8]Xiaoyun He, Yanhai Cheng,Lixuan Wang,Peng Huo: Coal technology, Vol.30(8)(2011), p.65(in Chinese)

[9]Zhenfa Liu,Dong Li, Yanji Wang, Lihui Zhang, Ruhui Guo: Technology of water treatment, Vol.30(5)(2004), p.300(in Chinese) 